\title{
ICMS Ecológico: análise de alternativas para sua implementação no estado da Bahia
}

\author{
Ecological ICMS: analysis of alternatives for its implementation in the state of Bahia - \\ Brazil
}

Daniel Souto Novaes ${ }^{1}$
Monica Moura Pires

\section{Palavras-chave}

ICMS Ecológico

Instrumentos Econômicos e Jurídicos

Indicadores de Sustentabilidade

\begin{abstract}
Resumo
Este trabalho analisa alternativas para a implementação do ICMS ecológico no estado da Bahia. Com esse propósito foram estimados os valores repassados aos municípios baianos, a título de ICMS, conforme as regras vigentes (LCE n. 13/1997), comparando a situação observada com os cenários de implementação dos projetos de lei n. 76/2006 e 15.502/2006 e através da utilização de um indicador de sustentabilidade proposto neste trabalho. Os cálculos foram feitos considerando os anos 2006 e 2016. Para análise da proposta relativa ao indicador de sustentabilidade foi elaborado um índice para cada município baiano que, uma vez utilizado no cálculo do repasse do ICMS, fosse capaz para compensar, financeiramente, os municípios que adotam políticas públicas de promoção da sustentabilidade. Para tanto foi utilizado foi o Indicador de Desenvolvimento Sustentável (IDS). Os resultados revelam que a implementação dos projetos de lei traria desvantagens pelo reduzido número de critérios adotados, enquanto a utilização do IDS propiciaria o tratamento da realidade municipal de modo mais holístico. De todo modo, em todas as situações analisadas os valores destinados aos critérios ecológicos são inexpressivos em comparação ao critério relacionado, exclusivamente, à produção econômica municipal.
\end{abstract}

\section{Keywords}

Ecological ICMS

Economic and Legal Instruments

Sustainability Indicators

\begin{abstract}
This paper analyzes alternatives for the implementation of ecological ICMS in the state of Bahia. With this purpose were estimated the values transferred to the municipalities of Bahia, as ICMS, according to the current rules (LCE 13/1997), comparing the situation observed with the implementation scenarios of bills n. 76/2006 and 15.502/2006 and through the use of a sustainability indicator proposed in this work. The calculations were made considering the years 2006 and 2016. In order to analyze the proposal for the
\end{abstract}

1Universidade Estadual de Santa Cruz. Email: danielsoutonovaes@yahoo.com.br

${ }^{2}$ Departamento de Ciências Econômicas da Universidade Estadual de Santa Cruz. Email: mpires@uesc.br 
sustainability indicator, an index was prepared for each municipality in Bahia, which, once used in the calculation of the ICMS transfer, was able to compensate financially the municipalities that adopt public policies to promote sustainability. For that, the Sustainable Development Indicator (IDS) was used. The results show that the implementation of the bills would bring disadvantages for the small number of criteria adopted, while the use of the IDS would facilitate the treatment of the municipal reality in a more holistic way. In any case, in all the analyzed situations the values destined to the ecological criteria are inexpressive in comparison to the criterion related exclusively to the municipal economic production.

\section{INTRODUÇÃO}

O termo ICMS Ecológico tem sido utilizado, de modo genérico, para referenciar a adoção de critérios relacionados com a manutenção da qualidade ambiental no momento em que os estados realizam os repasses obrigatórios de ICMS aos seus municípios.

Em linhas gerais, o ICMS é uma espécie de imposto incidente sobre a circulação de mercadorias e serviços e que foi constitucionalmente conferido aos estados da federação brasileira. Ao mesmo tempo em que conferiu tal prerrogativa aos estados, a mesma Constituição determinou, como política distributiva entre os entes federativos, que $25 \%$ do total arrecadado a título de ICMS fosse repartido com os respectivos municípios, sendo que $3 / 4$ desse montante (ou $18,75 \%$ do total) já devem ser disponibilizados conforme o Valor Adicionado (VA) produzido no território dos mesmos municípios, ficando a forma de distribuição do $1 / 4$ restante (ou $6,25 \%$ do total arrecadado) conforme critérios estabelecidos pela legislação estadual (BRASIL, 2018).

Os estados que adotaram o ICMS
Ecológico fizeram a opção de inserir critérios relacionados à proteção dos recursos naturais dentro dessa margem que a Constituição lhes conferiu o poder de disciplinar. Trata-se de instituto vinculado ao princípio do protetorrecebedor, através do qual defende-se que aquele que protege um bem natural, cujo benefício é revertido em prol da comunidade, receba uma compensação financeira como incentivo pelo serviço prestado. Tem-se, portanto, como benefício do instituto, a relativização da importância da produção econômica frente à preservação dos recursos naturais, reduzindo os impactos das desvantagens financeiras sofridas pelo município que opta por preservar ou mesmo por adotar atividades conservacionistas cujo resultado financeiro seja menos atrativo que a exploração predatória dos recursos.

O ICMS Ecológico encontra-se atualmente regulamentado em 16 estados da federação brasileira. Na Bahia não existe tal regulamentação, de modo que o tratamento da matéria se restringe à existência de propostas legislativas no âmbito da Assembleia Legislativa do Estado (BAHIA, 2006a; 2006b). 
Diante dessas questões traçou-se, como objetivo desse trabalho, avaliar duas alternativas para a regulamentação do ICMS Ecológico no estado da Bahia. A primeira alternativa é a que se extrai dos projetos legislativos mencionados e a segunda é uma proposta metodológica apresentada neste trabalho a partir da elaboração de um índice de desenvolvimento sustentável.

Com isso, redistribuem-se os recursos que seriam repartidos aos municípios baianos, caso adotadas cada uma dessas propostas. De posse desses dados, avaliou-se a correlação entre os valores distribuídos conforme critérios ambientais e os que são repartidos em decorrência de critérios exclusivamente relacionados ao incentivo da produção econômica.

Além desta introdução o trabalho está estruturado em quatro partes. $\mathrm{Na}$ parte da metodologia apresenta-se as discussões a respeito da repartição do ICMS segundo os critérios vigentes na Bahia. Em seguida, a forma de estimação do ICMS Ecológico em caso de implementação dos projetos de lei em tramitação na Assembleia Legislativa da Bahia, bem como em caso de adoção da proposta de cálculo dessa repartição a partir da utilização de indicadores de sustentabilidade. Nos resultados são expostos os elementos condutores das discussões a respeito da implementação de cada uma das propostas analisadas e na conclusão são expostas as críticas a essas propostas, indicando aquela que, conforme preconiza o instituto do ICMS Ecológico, seria mais eficiente no sentido de incentivar os municípios à adoção de práticas sustentáveis em seus territórios.

\section{METODOLOGIA}

A Bahia é a quinta unidade federativa do Brasil em extensão territorial, com uma área de $564.732,45 \mathrm{Km} 2$, que representa $6,64 \%$ do território nacional e $36,34 \%$ da região Nordeste, segundo o IBGE. Possui uma população de 14.016.906 habitantes e uma densidade demográfica de 24,82 hab/ $\mathrm{km}^{2}$; sendo o quarto Estado mais populoso do Brasil e o $15^{\circ}$ em povoamento (BRASIL, 2018).

De acordo com o IBGE, no território baiano existem três biomas: Mata Atlântica, compreendendo 19,29\% do território, Cerrado, com $26,87 \%$, e Caatinga, com 53,84\%.

Embora, por determinação constitucional, a repartição dos recursos do ICMS seja realizada por município, optou-se por condensar e apresentar os resultados por bioma do estado baiano, a fim de retratar mais adequadamente um conjunto de municípios que se inserem em condições ambientais semelhantes. Dessa forma, expõem-se especificidades de cada um desses territórios, subsidiando-se assim na implementação das políticas públicas aqui também analisadas. $\mathrm{Na}$ Tabela 1 tem-se a distribuição territorial e populacional da Bahia conforme os biomas. 
Tabela 1 - Quantidade de municípios da Bahia segundo o bioma predominante, ano de 2010.

\begin{tabular}{ccccc}
\hline Bioma & $\begin{array}{c}\text { Número de } \\
\text { Municípios }\end{array}$ & $\begin{array}{c}\text { População } \\
\text { (hab.) }\end{array}$ & $\begin{array}{c}\text { Área } \\
\left(\mathrm{Km}^{2}\right)\end{array}$ & $\begin{array}{c}\text { Densidade } \\
\text { Demográfica } \\
\left(\mathbf{h a b}^{2} \mathbf{K m}^{2}\right)\end{array}$ \\
\hline $\begin{array}{c}\text { Caatinga } \\
\text { Cerrado }\end{array}$ & 213 & 4.962 .962 & $314.299,077$ & 15,8 \\
Mata Atlântica & 33 & 724.662 & $138.492,018$ & 5,2 \\
\hline Total & 171 & 8.329 .282 & $111.941,355$ & 74,4 \\
\hline
\end{tabular}

Fonte: BRASIL, 2018.

Para os municípios no qual seu território está presente em mais de um bioma, considerou-se a predominância, avaliada segundo a extensão de ocorrência da unidade biológica no dado território.

Cálculo do repasse do ICMS segundo os critérios vigentes (LCE n. 13/1997)

$\mathrm{Na}$ Bahia, a repartição do ICMS é objeto da Lei Complementar Estadual (LCE) n. 13/1997 (BAHIA, 1997) que dispõe que a parcela do tributo disponível à disciplina estadual (6,25\% do total arrecadado) é repartida nas seguintes proporções: a) $40 \%$ considerando-se a proporção da população existente em cada município e o total da população do Estado; b) $30 \%$ considerando-se a proporção entre a área geográfica do Município e a total do Estado; c) $30 \%$ distribuídos igualitariamente aos municípios de baixa arrecadação no tocante ao valor adicionado (VA).

Para fracionar as cotas-parte dos 417 municípios baianos, a LCE n. 13/1997 determina que a cada um deles seja atribuído: um índice correspondente ao VA das operações mercantis ocorridas em seu território; outro correspondente à proporção de sua população em relação à população do Estado; outro proporcional ao seu território em relação ao do Estado; e, por fim, um índice que é específico para os municípios agraciados com a cota parte igualitária.

Tais índices, somados, correspondem ao Índice de Participação do Município (IPM), que, por sua vez, representa, proporcionalmente, a fatia que cada município receberá a título de repartição do ICMS. Por fim, os valores totais recebidos por cada município são divulgados, mensalmente, pela Secretaria da Fazenda do Estado da Bahia (SEFAZ/BA).

Assim, a etapa inicial do presente estudo foi, justamente, calcular, em termos monetários, a fração que representa, isoladamente, cada um daqueles índices nos repasses realizados aos municípios baianos, para então compará-los com os que seriam possíveis caso esses critérios fossem parcial ou completamente substituídos por critérios ambientais.

Nesse intuito foram escolhidos os repasses ocorridos nos anos de 2006 e 2016, com base nos índices apurados nos anos imediatamente anteriores. A consideração de dois anos distintos, bem como o interstício de 10 (dez) anos entre eles, deu-se para evitar que eventuais distorções ocorridas em um ano ou 
em uma sequência curta de anos prejudicassem a análise.

Assim, é possível distinguir os repasses realizados aos municípios baianos em decorrência de cada um dos critérios elencados pela LCE n. 13/1997, ou seja, em virtude do valor adicionado, da população, da extensão territorial e da parte igualitária.

Nas etapas seguintes realizou-se, com a utilização dos dados apurados na forma anteriormente mencionada, a estimativa da redistribuição desses recursos em caso de implementação das iniciativas legislativas existentes na Assembleia Legislativa da Bahia ou, conforme proposto nesta pesquisa, se fossem adotados indicadores de desenvolvimento sustentável.

\section{O ICMS Ecológico na Bahia: iniciativas legislativas}

As iniciativas atinentes à modificação dos critérios tradicionais para o repasse do ICMS no Estado da Bahia receberam o título de "ICMS Cidadão" e se encontram pautadas, fundamentalmente, no Projeto de Lei Complementar Estadual (PLCE) n ${ }^{\circ}$ 76/2006 da lavra do deputado estadual José Nunes e do Projeto de Lei Estadual (PLE) n. 15.502/2006 do deputado José Neto. Ambos os projetos propõem-se a alterar a LCE $n^{\circ} 13 / 1997$, no que tange à distribuição da parcela do ICMS pertencente aos municípios baianos.

O PLCE n. 76/2006 sugere que que a parcela do tributo disponível à disciplina estadual seja repassada aos municípios da seguinte forma: a) $40 \%$ proporcionalmente à população municipal em relação à do Estado; b) $25 \%$ considerando a proporção da área geográfica municipal e do Estado; c) $30 \%$ distribuídos equitativamente entre os municípios; e c) $5 \%$ considerando questões ambientais, sendo que, desse percentual, 50\% seriam distribuídos aos municípios que possuam sistema de tratamento ou disposição final de lixo ou de esgoto sanitário, com operação licenciada pelo órgão ambiental estadual, e 50\%, distribuídos com base no denominado Índice de Conservação Municipal (ICM), considerando-se as Unidades de Conservação (UC) existentes no território do município.

O PLE $\mathrm{n}^{\circ}$ 15.502/2006 adota tanto o percentual de $5 \%$ como os próprios critérios ambientais (unidades de conservação e políticas de saneamento ambiental). Esse projeto apenas complementa o primeiro ao acrescentar que as UC a serem consideradas, para efeito de repasse, necessariamente deveriam encontrar-se estabelecidas conforme Lei Federal n. 9.985/2000, que instituiu o Sistema Nacional de Unidades de Conservação (SNUC)

\section{Fatores de saneamento ambiental}

O primeiro critério ambiental previsto no PLCE n. 76/2006 foi o de saneamento, considerando, para tanto, a existência de pelo menos um desses serviços: tratamento ou disposição final de lixo ou de esgoto sanitário.

Esses dados foram coletados dos censos 
demográficos de 2000 e 2010 e das Pesquisas Nacionais de Saneamento Básico, realizadas pelo IBGE nos anos de 2000 e 2008, além das pesquisas do Sistema Nacional de Informações sobre Saneamento (SNIS), vinculado ao Ministério das Cidades.

A partir dessas fontes, identificamos os municípios que contavam com um desses serviços nos anos de 2005 e 2015 e dividimos valores equivalentes a 50\% (cinquenta por cento) do percentual destinado pelo PLCE $n$. 76/2006 aos critérios ecológicos.

\section{Índice de conservação municipal}

O segundo critério adotado pelo PLCE n. 76/2006 foi o ICM. Ocorre que não foram definidos parâmetros para a elaboração desse índice. Diante da necessidade de fixação desses parâmetros, utilizaremos, no presente estudo, metodologia semelhante à que vem sendo aplicada pelo Estado de Minas Gerais desde a edição de sua Lei Estadual n. 18.030/09 (MINAS GERAIS, 2018), para a obtenção de índice equivalente, com as adaptações necessárias à realidade jurídica do estado da Bahia e às disposições contidas nos citados projetos de lei.

Nestes termos, o ICM é obtido através da seguinte fórmula:

$\mathrm{ICMj}=\frac{\mathrm{FCMj}}{\sum \mathrm{j}}$
Em que: a) ICMj - é o Índice de Conservação de determinado Município; b) FCMj - é o fator de conservação do município “j”. A expressão do FCM é obtida por:

$\mathrm{FCMj}=\left(\frac{\mathrm{AEuc}}{\mathrm{Amj}}\right) \cdot \mathrm{Fq} \cdot \mathrm{Fc}$

Em que: b.1) AEucj - corresponde à área ocupada pelas Unidades de Conservação no município “j”; b.2) Amj - representa a área total do município “j”; b.3) Fc - corresponde ao fator atribuído à espécie de UC. Na legislação mineira, são categorizados 18 tipos de UC, sendo que cada um desses possui um fator de conservação pré-estabelecido; b.4) $\mathrm{Fq}$ corresponde a fator de qualidade física da UC, assumindo valores de 0,1 a 1 conforme determinados critérios são atendidos.

Os Fatores de Conservação (FC) foram estabelecidos conforme o legislador julgou haver maior ou menor restrição ao uso alternativo do solo (RODRIGUES, 2014). Para sua adoção no presente trabalho, algumas alterações fizeram-se necessárias, visto que o PLE n. 15.502/2006 restringe as UC àquelas integrantes do SNUC, no qual, diferentemente da mineira, apenas são previstas duas classes, as Unidades de Proteção Integral e Unidades de Uso Sustentável. Adaptando as duas propostas elaboramos o Quadro 1, utilizado para aferir o FC das UC avaliadas nesta pesquisa. 
Quadro 1 - Proposta de Fatores de Conservação para o Estado da Bahia

\begin{tabular}{|c|c|c|c|}
\hline \multicolumn{2}{|c|}{ CATEGORIAS DE UNIDADES DE CONSERVACÃO } & CÓDIGO & $\begin{array}{c}\text { FATOR DE CONSERVAÇÃO } \\
\text { DE CONSERVACO }\end{array}$ \\
\hline \multirow{5}{*}{$\begin{array}{c}\text { I - UNIDADES DE } \\
\text { PROTEÇÃO INTEGRAL }\end{array}$} & Estação Ecológica & $\mathrm{EE}$ & 1,0 \\
\hline & Reserva Biológica & $\mathrm{RB}$ & 1,0 \\
\hline & $\begin{array}{c}\text { Parque Nacional, Estadual e Municipal } \\
\text { Natural }\end{array}$ & $\mathrm{PQ}$ & 1,0 \\
\hline & Refúgio da Vida Silvestre & RVS & 1,0 \\
\hline & Monumento Natural & $\mathrm{MN}$ & 1,0 \\
\hline \multirow{7}{*}{$\begin{array}{l}\text { II - UNIDADES DE } \\
\text { USO SUSTENTÁVEL }\end{array}$} & Reserva Particular do Patrimônio Natural & RPPN & 1,0 \\
\hline & Área de Proteção Ambiental & APA & 0,5 \\
\hline & Reserva Extrativista & RESEX & 0,5 \\
\hline & Reserva de Desenvolvimento Sustentável & REDES & 0,5 \\
\hline & Floresta Nacional, Estadual e Municipal & FLO & 0,3 \\
\hline & Reserva de Fauna & $\mathrm{RF}$ & 0,3 \\
\hline & Área de Relevante Interesse Ecológico & ARIE & 0,3 \\
\hline
\end{tabular}

Fonte: Elaborado pelos Autores, adaptado da Lei n. 18.030/09 do Estado de Minas Gerais.

Quanto aos Fatores de Qualidade (FQ) foram utilizados os que são definidos pela Deliberação Normativa n. 86/2005 do COPAM/MG (MINAS GERAIS, 2005), que avaliam aspectos estruturais das unidades de conservação. A avaliação desses critérios é realizada pelo gestor da unidade, conforme barema contido no corpo da própria Deliberação Normativa 86/2005 o qual é encaminhado, juntamente aos respectivos documentos comprobatórios, ao Instituto Estadual de Florestas de Minas Gerais (IEF/MG).

Para responder ao propósito da presente pesquisa, o mesmo barema foi respondido pelos pesquisadores conforme a disponibilidade dos dados no Cadastro Nacional de Unidades de Conservação (CNUC), realizado pelo Ministério do Meio Ambiente (MMA) e do Instituto Estadual do Meio Ambiente e Recursos Hídricos (INEMA).

Por fim, tendo em vista a determinação contida no $\S 3^{\circ}$ do art. 27 da Lei do SNUC (Lei Federal n. 9.985/00), segundo a qual "o Plano de Manejo de uma unidade de conservação deve ser elaborado no prazo de cinco anos a partir da data de sua criação", não foram incluídas na análise as UC que, nos anos de 2005 e 2015, já contavam mais de cinco anos de instituição e que ainda não possuíam plano de manejo aprovado. Trata-se de medida de compatibilização entre os termos da proposta de legislação ao já disposto no estatuto federal, obstando que situações de flagrante ilegalidade sejam agraciadas através do repasse de ICMS.

Estabelecidos tais parâmetros, a etapa seguinte foi identificar os municípios que possuíam UC que atendiam a tais requisitos, nos anos de 2005 e 2015, resultando, consequentemente, em maior repasse de ICMS nos anos de 2006 e 2016 .

Para estimar as áreas ocupadas pelas UC nos territórios municipais, foi utilizado o software livre para criação de mapas interativos e geoprocessamento "i3Geo" disponibilizado no sítio eletrônico do MMA.

Após estimar o ICM de cada um dos 
municípios baianos foram redistribuídos, em proporção aos índices estimados, os valores equivalentes a $50 \%$ do percentual destinado pelo PLCE n. 76/2006 aos critérios ecológicos.

Cálculo do índice de desenvolvimento sustentável (IDS)

A etapa seguinte foi a estimação do repasse de ICMS segundo proposta desta pesquisa, qual seja a utilização de um índice de sustentabilidade. O objetivo é que tal índice, reflita ao mesmo tempo em que a realidade socioambiental no âmbito dos municípios, e sirva para compensar, financeiramente, os municípios que tenham adotado políticas públicas voltadas à promoção dessa sustentabilidade. Nos estritos termos desses objetivos calculou-se o IDS dos municípios baianos, para os anos de 2006 e 2016.

A metodologia utilizada baseou-se na proposta de Sepúlveda (SEPÚLVEDA, 2008), com as adaptações necessárias diante do foco da presente pesquisa, das fontes disponíveis de dados e, também, da conveniência de integração da proposta a outras metodologias já internalizadas no âmbito governamental do estado da Bahia.

Em linhas gerais, a proposta de Sepúlveda procura criar um instrumento de análise da sustentabilidade de territórios rurais. Para tanto, propõe a sistematização de seis dimensões - Econômica, Demográfica, Social, Político-Institucional, Ambiental e Cultural -, sendo que cada uma, por sua vez, é avaliada segundo uma série de variáveis, cujos dados, condensados em um índice, visam a demonstrar o equilíbrio das ações exercidas no dado território. Para cada uma dessas variáveis foi atribuída uma nota, variando entre 0 e 1 , sendo que 1 representa a melhor situação encontrada em termos de sustentabilidade e $0, \quad$ o extremo oposto. Conforme Quadro 3:

Quadro 2 - Barema de Sepúlveda, utilizado para avaliação do IDS dos municípios baianos

\begin{tabular}{|c|c|}
\hline Classe & Avaliação \\
\hline $0 \leq$ IDS $<0,2$ & Colapso \\
\hline $0,2 \leq$ IDS $<0,4$ & Crítico \\
\hline $0,4 \leq$ IDS $<0,6$ & Instável \\
\hline $0,6 \leq$ IDS $<0,8$ & Estável \\
\hline $0,8 \leq$ IDS $\leq 1$ & Ótimo \\
\hline
\end{tabular}

Fonte: Sepúlveda (2008), adaptação e tradução dos autores.

Por sua vez, o IDS é calculado a partir da média simples das notas das variáveis que compõem essas seis dimensões, formando seis índices independentes, são eles: Índice Demográfico ou de População (IPOP), Índice Social (IS), Índice de Desenvolvimento Econômico (IECO), Índice de Meio Ambiente (IMA), Índice Político-Institucional (IPOI) e Índice de Desenvolvimento Cultural (IDC), através da seguinte fórmula:

$\mathrm{IDS}=\frac{\mathrm{IPOP}+\mathrm{IS}+\mathrm{IECO}+\mathrm{IMA}+\mathrm{IPOI}+\mathrm{IDC}}{6}$

As variáveis utilizadas na presente pesquisa foram: densidade demográfica, taxa da urbanização e taxa de envelhecimento para compor o IPOP; Índice de Performance Social, mortalidade infantil até 1 ano de idade e número de homicídios por 100 mil habitantes 
para o IS; Índice de Performance Econômica e Índice de Gini-Renda para o IECO; taxas de Coleta e de tratamento de resíduos sólidos e esgoto e o Índice de Conservação Municipal para o IMA; taxa de não comparecimento às eleições, número médio de conselhos municipais e acesso à justiça para o IPOI; e o número de bibliotecas, centros de inclusão digital, clubes, ginásios de esportes e estádios, cinemas e unidades de ensino superior para o IDC.

Foram coletados, fundamentalmente, dados secundários de instituições oficiais referentes a dois momentos distintos, 2005 e 2015 (para fixação dos percentuais a serem repassados nos anos subsequentes), permitindo-se uma análise evolutiva do IDS.

Para encontrar a quota-parte que seria destinada a cada município foram redistribuídos, proporcionalmente aos respectivos IDS, os valores correspondentes a $25 \%$ do total de ICMS arrecadado no Estado da Bahia nos anos de 2006 e 2016.

\section{Correlação entre os Resultados Encontrados}

A partir dos dados obtidos conforme processo descrito nas etapas anteriores, fundamentalmente os valores atualmente repassados aos municípios baianos através da LCE n. 13/1997 e os que seriam repassados conforme os critérios ambientais previstos no PLCE n. 76/2006 e na fórmula proposta pelo uso do IDS, foi analisada a correlação desses valores através da Correlação Linear de Pearson.
O referido teste permite a obtenção de um índice (entre $-1,0$ e 1,0) que reflete a intensidade da relação linear entre dois conjuntos de dados, sendo que os valores positivos indicam que quanto maiores os valores de uma variável, maiores os valores da outra associada e os negativos refletem o inverso. Os valores próximos a 1 e -1 indicam uma relação linear intensa e os valores próximos a 0 indicam uma fraca relação linear (NAVIDI, 2012).

Entende-se que este instrumento serve a avaliar a equidade na distribuição dos recursos, pois aponta possíveis tendências de superposição, ou seja, se municípios que já são mais agraciados com determinado critério de repartição do ICMS tendem, ou não, a serem mais em outro critério.

\section{RESULTADOS E DISCUSSÃO}

A seguir são apresentadas as estimações dos valores que seriam repassados aos municípios baianos segundo cada um dos critérios adotados neste estudo, conforme metodologia descrita no item 2.

a) LCE n. 13/1997

Segundo a SEFAZ (BAHIA, 2018), no ano de 2006 a arrecadação total de ICMS no Estado da Bahia ficou em $\mathrm{R} \$ 7,69$ bilhões. Desse montante, foram repassados $\mathrm{R} \$ 1,93$ bilhões aos municípios. Deflacionando esse valor, pelo IGP-DI, mês-base dezembro de 2016, e redistribuindo-o segundo os critérios elencados 
pela LCE n. 13/1997 (Tabela 2).

Tabela 2 - Repartição do ICMS no Estado da Bahia segundo critérios da LCE n. 13/1997, por biomas do Estado.

\begin{tabular}{|c|c|c|c|c|c|c|}
\hline Bioma & $\begin{array}{c}\text { Valor } \\
\text { Adicionado } \\
(\mathrm{R} \$)\end{array}$ & $\begin{array}{l}\text { População } \\
\text { (R\$) }\end{array}$ & $\begin{array}{l}\text { Área } \\
(\mathrm{R} \$)\end{array}$ & $\begin{array}{c}\text { Parte } \\
\text { Igualitária } \\
(\mathrm{R} \$)\end{array}$ & $\begin{array}{c}\text { Total por Bioma } \\
(\mathrm{R} \$)\end{array}$ & $\%$ \\
\hline \multicolumn{7}{|c|}{2006} \\
\hline Caatinga & $401.989 .044,50$ & $131.914 .778,88$ & $153.497 .077,76$ & $153.543 .132,89$ & $840.944 .034,03$ & 23 \\
\hline Cerrado & $194.839 .697,98$ & $17.977 .013,75$ & $68.066 .553,74$ & $20.162 .232,88$ & $301.045 .498,35$ & 8 \\
\hline $\begin{array}{c}\text { Mata } \\
\text { Atlântica }\end{array}$ & 2.179.355.569,91 & $220.266 .091,01$ & $56.054 .801,24$ & $103.913 .046,97$ & 2.559.589.509,13 & 69 \\
\hline TOTAL & $2.776 .184 .312,39$ & $370.157 .883,64$ & $277.618 .412,74$ & $277.618 .412,74$ & $3.701 .579 .041,51$ & 100 \\
\hline \multicolumn{7}{|c|}{2016} \\
\hline Caatinga & $519,319,670,98$ & $165,236,974,03$ & $195,626,103,34$ & $192.520 .293,19$ & $1.072 .703 .041,54$ & 23 \\
\hline Cerrado & $300.152 .876,83$ & $23.857 .077,49$ & $85.851 .302,62$ & $24.556 .167,76$ & $434.417 .424,69$ & 9 \\
\hline Mata & $2.716 .614 .819,70$ & $282.384 .264,15$ & $72.131 .330,79$ & $136.532 .275,80$ & $3.207 .662 .690,44$ & 68 \\
\hline Atlântica & & & & & & \\
\hline Total & $3.536 .087 .367,50$ & $471.478 .315,67$ & $353.608 .736,75$ & $353.608 .736,75$ & $4.714 .783 .156,67$ & 100 \\
\hline
\end{tabular}

No ano de 2016, a arrecadação de ICMS no Estado da Bahia alcançou o montante de $\mathrm{R} \$ 19,4$ bilhões, sendo repartido com os municípios o total de $\mathrm{R} \$ 4,7$ bilhões (BAHIA, 2018). Embora tenha havido um incremento na arrecadação, ao se analisar a distribuição dos recursos dentro do território baiano foi possível perceber que as circunstâncias mantiveram-se praticamente inalteradas Vêse, portanto, que nos dois anos, cerca de $70 \%$ dos recursos repartidos no Estado da Bahia, a título de ICMS, ficaram com os municípios integrantes do Bioma Mata Atlântica.

É possível apontar razões históricas para essa concentração, visto que as áreas próximas ao litoral, onde predomina a Mata Atlântica, foram mais intensamente povoadas no Brasil, desde o período colonial, não sendo diferente na Bahia, na qual os municípios litorâneos concentram cerca de $60 \%$ da população e oito entre os dez principais deles em termos de
Produto Interno Bruto (PIB). Ou seja, os municípios da região da Mata Atlântica encontram-se em estágio mais avançado quanto à presença de atividades econômicas, o que resulta em um volume comercial mais intenso e, consequentemente, em maiores repasses no tocante ao VA.

Reforçando o exposto, a Tabela 3 expõe uma relação entre a soma das áreas dos territórios dos municípios analisados e os repasses decorrentes, exclusivamente, do critério VA.

Essa abordagem demonstra o potencial econômico que seria perdido quando uma área de terra é "retirada" do processo produtivo para fins de conservação (FERNANDES, 2011), conferindo ao gestor municipal um importante indicador do possível impacto dessas ações nas finanças locais (GRIEGGRAN, 2000). 
Tabela 3 - Repartição do VA no Estado da Bahia, por área dos biomas

\begin{tabular}{|c|c|c|c|}
\hline Bioma & $\begin{array}{l}\text { Valor Adicionado } \\
(\mathbf{R} \$)\end{array}$ & $\begin{array}{l}\text { Área } \\
\left(\mathrm{Km}^{2}\right)\end{array}$ & $\begin{array}{l}\text { Valor Adicionado por Área } \\
\left(\mathrm{R} \$ / \mathrm{km}^{2}\right)\end{array}$ \\
\hline \multicolumn{4}{|c|}{2006} \\
\hline Caatinga & $401.989 .044,50$ & $314.299,077$ & $1.279,00$ \\
\hline Cerrado & $194.839 .697,98$ & $138.492,018$ & $1.406,87$ \\
\hline Mata Atlântica & $2.179 .355 .569,91$ & $111.941,355$ & $19.468,73$ \\
\hline Total & $2.776 .184 .312,39$ & $564.732,450$ & $4.915,93$ \\
\hline \multicolumn{4}{|c|}{2016} \\
\hline Caatinga & $519.319 .670,98$ & $314.299,077$ & $1.652,31$ \\
\hline Cerrado & $300.152 .876,83$ & $138.492,018$ & $2.167,29$ \\
\hline Mata Atlântica & $2.716 .614 .819,70$ & $111.941,355$ & $24.268,20$ \\
\hline Total & $3.536 .087 .367,50$ & $564.732,450$ & $6.261,53$ \\
\hline
\end{tabular}

\section{b) PLCE 76/2006 e do PLE 15.502/2006}

A redução, de $7,5 \%$ para $6,25 \%$, na importância do critério área, representaria, aproximadamente, $\mathrm{R} \$ 46,2$ e 59,0 milhões, respectivamente nos anos de 2006 e 2016, valores equivalentes, portanto, a $1,25 \%$ do total de ICMS a ser repartido com os municípios e que, de acordo com o PLCE $n$. 76/2006, deve ser destinado conforme critérios ecológicos. Redistribuindo tais recursos (Tabela 4).

Tabela 4 - Repartição do ICMS no Estado da Bahia segundo critérios do PLCE n. 76/2006, por biomas do Estado

\begin{tabular}{|c|c|c|c|c|c|c|c|}
\hline Bioma & $\begin{array}{c}\text { Valor } \\
\text { Adicionado } \\
(\mathrm{R} \$)\end{array}$ & $\begin{array}{c}\text { População } \\
\text { (R\$) }\end{array}$ & $\begin{array}{c}\text { Área } \\
(\mathrm{R} \$)\end{array}$ & $\begin{array}{c}\text { Parte } \\
\text { Igualitária } \\
(\mathbf{R} \$)\end{array}$ & $\begin{array}{c}\text { Critérios } \\
\text { Ambientais } \\
(\mathrm{R} \$)\end{array}$ & $\begin{array}{c}\text { Total por } \\
\text { Bioma } \\
(\mathrm{R} \$)\end{array}$ & $\%$ \\
\hline \multicolumn{8}{|c|}{2006} \\
\hline Caatinga & $401.988 .949,97$ & $131.914 .778,88$ & $127.914 .213,78$ & $153.543 .132,89$ & $8.972 .030,60$ & $824.333 .106,12$ & 22 \\
\hline Cerrado & $194.839 .683,33$ & $17.977 .013,75$ & $56.722 .128,28$ & $20.162 .232,88$ & $1.156 .743,39$ & $290.857 .801,62$ & 8 \\
\hline Mata & $2.179 .355 .493,99$ & $220.266 .091,01$ & $46.712 .335,21$ & $103.913 .046,96$ & $36.140 .961,47$ & $2.586 .387 .928,65$ & 70 \\
\hline Atlântica & & & & & & & \\
\hline Total & 2.776.184.127,29 & $370.157 .883,64$ & $231.348 .677,27$ & $370.157 .883,64$ & $46.269 .735,45$ & $3.701 .578 .836,39$ & 100 \\
\hline \multicolumn{8}{|c|}{2016} \\
\hline Caatinga & $519.319 .670,98$ & $165.236 .974,03$ & $163.021 .752,78$ & $192.520 .293,19$ & $23.740 .317,72$ & $1.063 .839 .008,70$ & 23 \\
\hline Cerrado & $300.152 .876,83$ & $23.857 .077,49$ & $71.542 .752,19$ & $24.556 .167,76$ & $3.777 .871,07$ & $423.886 .745,34$ & \multirow{2}{*}{$\begin{array}{r}9 \\
68\end{array}$} \\
\hline $\begin{array}{c}\text { Mata } \\
\text { Atlântica }\end{array}$ & $2.716 .614 .819,70$ & $282.384 .264,15$ & $60.109 .442,32$ & $136.532 .275,80$ & $31.416 .600,66$ & $3.227 .057 .402,63$ & \\
\hline Total & $3.536 .087 .367,50$ & $471.478 .315,67$ & $294.673 .947,29$ & $353.608 .736,75$ & $58.934 .789,45$ & $4.714 .783 .156,67$ & 100 \\
\hline
\end{tabular}

Outra maneira de se avaliar o impacto da implementação do ICMS Ecológico é observando a relação entre os valores que seriam recebidos pelos municípios em decorrência dos critérios ecológicos com a área ocupada pelos municípios (Tabela 5).

Infere-se, portanto, que os municípios baianos receberiam, como média geral $\mathrm{R} \$ 4,9$ mil em 2006 e $\mathrm{R} \$ 6,2$ mil em 2016, por área, considerando-se apenas o VA, e $\mathrm{R} \$ 81,93$ e $\mathrm{R} \$ 104,36$, respectivamente, em decorrência exclusivamente dos critérios ecológicos. Essa relação é ainda mais desproporcional se considerados, apenas, os municípios da Mata Atlântica, na qual os montantes recebidos em decorrência do VA foram de $\mathrm{R} \$ 19,4$ mil e $\mathrm{R} \$ 24,2$ mil em 2006 e 2016, respectivamente, enquanto, se adotados os critérios ecológicos, ficariam em $\mathrm{R} \$ 322,9$ e $\mathrm{R} \$ 280,7$, nos respectivos anos. 
Tabela 5 - Repartição dos valores decorrentes dos critérios ambientais do PLCE n. 76/2006, por área dos municípios em cada um dos biomas baianos,

\begin{tabular}{|c|c|c|c|}
\hline Bioma & $\begin{array}{c}\text { Critérios Ambientais } \\
(\mathrm{R} \$)\end{array}$ & $\begin{array}{l}\text { Área } \\
\left(\mathrm{Km}^{2}\right)\end{array}$ & $\begin{array}{c}\text { Valor Relativo aos } \\
\text { Critérios Ambientais por } \\
\text { Área }\left(\mathrm{R} \$ / \mathrm{km}^{2}\right)\end{array}$ \\
\hline \multicolumn{4}{|c|}{2006} \\
\hline Caatinga & $8.972 .030,60$ & $314.299,077$ & 28,55 \\
\hline Cerrado & $1.156 .743,39$ & $138.492,018$ & 8,35 \\
\hline Mata Atlântica & $36.140 .961,47$ & $111.941,355$ & 322,86 \\
\hline Total & $46.269 .735,45$ & $564.732,450$ & 81,93 \\
\hline \multicolumn{4}{|c|}{2016} \\
\hline Caatinga & $23.740 .317,72$ & $314.299,077$ & 75,53 \\
\hline Cerrado & $3.777 .871,07$ & $138.492,018$ & 27,28 \\
\hline Mata Atlântica & $31.416 .600,66$ & $111.941,355$ & 280,65 \\
\hline Total & $58.934 .789,45$ & $564.732,450$ & 104,36 \\
\hline
\end{tabular}

A atividade econômica renderia, em média, em torno de $1 / 60$ do que seria decorrente da média encontrada quando considerados, apenas, os valores recebidos em virtude do VA. Essa prevalência do critério VA revela-se concentradora de renda, pois prioriza o repasse dos recursos para os municípios mais ricos, fazendo aumentar a distância em relação aos mais pobres (ROCCO, 2004).

Assim, os municípios que apresentam maior crescimento econômico em detrimento da preservação ambiental são aquilatados com maior quantidade de repasses financeiros, além da inerente possibilidade de gerar receitas em função da circulação de mercadorias. Por outro lado, aqueles que arcam com a responsabilidade de preservar o bem natural, trazendo externalidades positivas que beneficiam a todos, sofrem restrições em sua capacidade de desenvolvimento econômico e ainda recebem menos repasses financeiros (SCAFF; TUPIASSU, 2005).

Além disso, a escolha da criação de UC como principal critério de repasse pode fomentar um tratamento desigual aos biomas observados no território, haja vista uma notável tendência do poder público a reconhecer a relevância de características encontradas em regiões de floresta ou de mata que não se repete na mesma intensidade no Cerrado ou na Caatinga, para citar dois exemplos do território baiano. Basta observar que, no Brasil, a Mata Atlântica e a Floresta Amazônica ocupam $62,33 \%$ do território brasileiro, e mais de $83 \%$ dos territórios protegidos (BRASIL, 2018).

Outro fator limitador do critério em questão é o de que esse reconhecimento, pelo Poder Público, da relevância de determinadas características naturais, dificilmente ocorrerá em áreas já degradadas. Com isso, os municípios que, no decorrer do processo histórico, tenham degradado seus recursos naturais não terão, no instituto em análise, um estímulo à recuperação, quando sopesado o volume de recursos a serem empregados e o longo prazo necessário para a recuperação dessas áreas, mormente ao ponto de virem a ser consideradas "relevantes", nos termos da lei do SNUC.

Sobre o tratamento de lixo e esgoto, de 
acordo com os dados da presente pesquisa, cada município que tivesse implementado tratamento de lixo ou de esgoto receberia, no ano de 2006, um repasse de $\mathrm{R} \$ 578,3$ mil e em 2016 , tal repasse seria de $\mathrm{R} \$ 755,5$ mil. Tais valores podem ser considerados relevantes na medida em que se aproximam do valor médio, por exemplo, do que é repartido com os municípios em decorrência do critério área, os quais foram, em 2006 , $\mathrm{R} \$ 589,4$ mil e $\mathrm{R} \$ 847,9$ mil em 2016. Entretanto, a sistemática adotada pelo PLCE n. 76/2006 também não está imune a críticas quanto a esses dois critérios.

A redação do projeto de lei é taxativa ao afirmar que $50 \%$ dos recursos deveriam ser repassados aos municípios que possuam tratamento de lixo ou de esgoto. Logo, nos termos propostos, ocorre uma exclusão dos critérios, de modo que um município que já tenha implementado o tratamento de esgoto em seu território não estaria "incentivado" a realizar o tratamento de seus resíduos sólidos, visto que o valor a ser recebido seria exatamente o mesmo, com ou sem a implementação do segundo serviço.

Outra crítica é que o PLCE n. 76/2006 não acrescenta quaisquer critérios qualitativos, permitindo, assim, que municípios dotados de serviços absolutamente inexpressivos quanto ao volume de tratamento de resíduos sólidos ou esgoto recebam o mesmo montante de recursos daqueles que tratam todos os seus resíduos.

c) Índice de desenvolvimento sustentável - IDS

No cálculo do IDS dos municípios baianos a partir de dados colhidos até o ano de 2005 (visando ao repasse a ser utilizado no ano de 2006), a média geral do Estado foi de 0,35, o que representa uma situação crítica sob o ponto de vista da sustentabilidade (Tabela 6). No ano de 2016 verificou-se uma pequena melhora em relação à avaliação anterior; a média geral da Bahia ficou em 0,43, um patamar considerado instável segundo o mesmo parâmetro.

Tabela 6 - IDS por bioma do território baiano

\begin{tabular}{|c|c|c|c|c|c|c|c|}
\hline Bioma & Média & Mediana & $\begin{array}{l}\text { Desvio } \\
\text { Padrão }\end{array}$ & $\begin{array}{l}\text { Menor } \\
\text { IDS }\end{array}$ & $\begin{array}{l}\text { Município } \\
\text { menor IDS }\end{array}$ & $\begin{array}{l}\text { Maior } \\
\text { IDS }\end{array}$ & $\begin{array}{l}\text { Município } \\
\text { Maior IDS }\end{array}$ \\
\hline \multicolumn{8}{|c|}{2006} \\
\hline Caatinga & 0,33 & 0,34 & 0,06 & 0,16 & $\begin{array}{c}\text { Pedro } \\
\text { Alexandre }\end{array}$ & 0,50 & Brumado \\
\hline Cerrado & 0,32 & 0,32 & 0,06 & 0,22 & $\begin{array}{l}\text { Sebastião } \\
\text { Laranjeiras }\end{array}$ & 0,46 & Barreiras \\
\hline $\begin{array}{l}\text { Mata } \\
\text { Atlântica }\end{array}$ & 0,37 & 0,36 & 0,09 & 0,15 & Jucuruçu & 0,77 & Salvador \\
\hline Estado & 0,35 & 0,35 & 0,07 & 0,15 & Jucuruçu & 0,77 & Salvador \\
\hline \multicolumn{8}{|c|}{2016} \\
\hline Caatinga & 0,42 & 0,41 & 0,05 & 0,27 & Heliópolis & 0,60 & $\begin{array}{l}\text { Paulo } \\
\text { Afonso }\end{array}$ \\
\hline Cerrado & 0,39 & 0,39 & 0,04 & 0,32 & Santana & 0,47 & Coribe \\
\hline $\begin{array}{l}\text { Mata } \\
\text { Atlântica }\end{array}$ & 0,45 & 0,44 & 0,08 & 0,29 & Irajuba & 0,78 & Salvador \\
\hline Estado & 0,43 & 0,42 & 0,07 & 0,27 & Heliópolis & 0,78 & Salvador \\
\hline
\end{tabular}


Tais dados foram utilizados, nesta do montante repartido com os municípios pesquisa, para a repartição do percentual de $1 / 4 \quad$ baianos (Tabela 7).

Tabela 7 - Repartição do ICMS no Estado da Bahia segundo o IDS, por biomas do Estado

\begin{tabular}{ccccc}
\hline Bioma & $\begin{array}{c}\text { Valor Adicionado } \\
(\mathbf{R} \$)\end{array}$ & $\begin{array}{c}\text { IDS } \\
(\mathbf{R} \$)\end{array}$ & $\begin{array}{c}\text { Total por Bioma } \\
(\mathbf{R} \$)\end{array}$ & $\%$ \\
\hline Caatinga & & 2006 & & \\
Cerrado & $401.988 .949,97$ & $453.139 .158,88$ & $855.128 .108,85$ & 23 \\
Mata Atlântica & $194.839 .683,33$ & $66.869 .854,11$ & $261.709 .537,44$ & 7 \\
\hline Total & $2.179 .355 .493,99$ & $405.385 .696,13$ & $2.584 .741 .190,12$ & 70 \\
\hline Caatinga & $2.776 .184 .127,29$ & $925.394 .709,12$ & $3.701 .578 .836,41$ & 100 \\
\hline Cerrado & $519.319 .670,98$ & $587.578 .249,10$ & & $2.106 .897 .920,08$ \\
Mata Atlântica & $300.152 .876,83$ & $85.085 .457,16$ & $385.238 .333,99$ & 8 \\
\hline Total & $2.716 .614 .819,70$ & $506.032 .082,91$ & $3.222 .646 .902,61$ & 68 \\
\hline
\end{tabular}

A relação dos valores recebidos em decorrência da Dimensão Ambiental do IDS e a área dos municípios é apresentada na Tabela 8.

Tabela 8 - Repartição dos valores decorrentes da Dimensão Ambiental do IDS, por área dos biomas baianos

\begin{tabular}{|c|c|c|c|}
\hline Bioma & $\begin{array}{c}\text { Critérios Ambientais } \\
(\mathrm{R} \$)\end{array}$ & $\begin{array}{l}\text { Área } \\
\left(\mathrm{Km}^{2}\right)\end{array}$ & $\begin{array}{c}\text { Valor Relativo aos } \\
\text { Critérios Ambientais por } \\
\text { Área }\left(\mathrm{R} \$ / \mathrm{km}^{2}\right) \\
\end{array}$ \\
\hline \multicolumn{4}{|c|}{2006} \\
\hline Caatinga & $24.385 .213,21$ & $314.299,077$ & 77,59 \\
\hline Cerrado & $4.009 .810,92$ & $138.492,018$ & 28,95 \\
\hline Mata Atlântica & $28.374 .842,03$ & $111.941,355$ & 253,48 \\
\hline Total & $56.769 .866,16$ & $564.732,450$ & 100,52 \\
\hline \multicolumn{4}{|c|}{2016} \\
\hline Caatinga & $33.334 .939,40$ & $314.299,077$ & 106,06 \\
\hline Cerrado & $2.236 .185,35$ & $138.492,018$ & 16,15 \\
\hline Mata Atlântica & $39.943 .780,62$ & $111.941,355$ & 356,83 \\
\hline Total & $75.514 .905,37$ & $564.732,450$ & 133,72 \\
\hline
\end{tabular}

Observa-se pouca modificação em relação aos dados apresentados anteriormente, vez que os municípios da Mata Atlântica seguiram como os principais destinatários de recursos, em percentuais até muito próximos aos obtidos com base na LCE n.13/1997 (realidade vigente) e no PLCE n. 76/2006. Além disso, em uma média dos dois anos os municípios baianos receberiam cerca de 47 vezes mais recursos em decorrência do estimulo às atividades econômicas em seus territórios do que em contrapartida aos critérios ambientais.
Contudo, ao se analisar tais dados segundo visão holística é possível inferir que o incentivo para melhorar a avaliação do município em relação às dimensões demográfica, social, econômica, políticoinstitucional e cultural também produz resultados positivos no tocante ao meio ambiente, tendo em vista a interrelação entre esses fatores, que é, justamente, o que se pretende com a utilização do IDS. Ou seja, não é apenas a melhora dos critérios elencados na dimensão ambiental que produz resultados 
ambientalmente favoráveis. Sob esse viés, a disparidade encontrada entre os valores destinados aos critérios ambientais versus VA reduzir-se-ia consideravelmente.

A redução dessa disparidade não resolveria, no entanto, outra crítica comumente associada ao ICMS Ecológico, a de que ele reproduz um "jogo de soma zero". Isso porque, quanto maior o número de municípios que aderem a seus incentivos, menores serão os valores individuais, tendo em vista haver um teto global para os repasses (ROSSATO, 2008). Trata-se de problema inerente à existência de um limite para a implementação do ICMS Ecológico, e esse limite encontra-se estabelecido na CRFB/1988. Não obstante, o aumento dos percentuais destinados aos critérios ecológicos tem o potencial de adiar esse problema, elevando o "ponto de saturação" do sistema, que, no caso, corresponde ao ponto a partir do qual haveria redução nos repasses relativos aos municípios.

Ademais, ainda que se vislumbre, no futuro, uma redução do incentivo no tocante aos repasses ecológicos, essa redução é necessariamente paralela a uma melhora dos municípios em suas questões com o meio ambiente, o que, de per si, já seria salutar.

\section{Análise de correlação dos critérios analisados}

Aplicando o teste da correlação linear de Person aos valores recebidos em virtude de cada um dos critérios adotados pela LCE $n$.
13/1997 (VA, população, área e parte igualitária), verifica-se que os principais "arrecadadores" no tocante ao critério VA também são os maiores beneficiados da soma dos demais critérios legais, haja vista a correlação positiva e forte entre esses critérios (Tabela 9).

Quanto à correlação entre os repasses recebidos em virtude dos critérios ecológicos previstos no PLCE n. 76/2006 e aqueles decorrentes do VA, tem-se uma correlação negativa e fraca para o ano de 2006 e nula no ano de 2016, demonstrando não haver uma relação paralela entre o repasse ecológico e o repasse por força, meramente, das atividades produtivas.

Relacionando o VA com os valores que seriam repassados através do IDS, o índice de correlação foi positivo e moderado, ficando em 0,5. Estabelecendo a mesma relação entre os valores recebidos com base no critério VA e os que seriam provenientes apenas da Dimensão Ambiental do IDS, encontramos um índice de correlação também positivo, porém fraco, em aproximadamente 0,4 e 0,3 .

Nota-se, portanto, baixa correlação do IDS com o critério VA. Embora positiva em todos os cenários analisados, essa correlação mostrou-se fraca, situação bastante distinta da apresentada com LCE n. 13/1997. Essa baixa correlação tem a virtude de ampliar o espectro de avaliação dos municípios, impedindo a já mencionada sobreposição entre os critérios. 
Tabela 9 - Resultado da correlação de Pearson (r) entre variáveis, Bahia, 2006 e 2016.

\begin{tabular}{|c|c|c|}
\hline Correlação & 2006 & 2016 \\
\hline \multirow{2}{*}{$\begin{array}{l}\text { Valores recebidos pelos municípios baianos em decorrência do VA e da } \\
\text { soma dos critérios População, Área e Parte Igualitária }\end{array}$} & $\mathrm{r}=0,659323$ & $\mathrm{r}=0,732705$ \\
\hline & $\mathrm{p}=2,361519$ & $\mathrm{p}=2,305401$ \\
\hline \multirow{2}{*}{$\begin{array}{l}\text { Valores recebidos pelos municípios baianos em decorrência dos critérios } \\
\text { ecológicos previstos no PLCE } n \text {. } 76 / 2006 \text { e do VA }\end{array}$} & $r=-0,071545$ & $r=0,000185$ \\
\hline & $\mathrm{p}=0,144711$ & $\mathrm{p}=0,996993$ \\
\hline \multirow{2}{*}{$\begin{array}{l}\text { Valores recebidos pelos municípios baianos em decorrência do VA e do } \\
\text { IDS }\end{array}$} & $r=0,523728$ & $r=0,497558$ \\
\hline & $\mathrm{p}=9,530183$ & $\mathrm{p}=1,820174$ \\
\hline \multirow{2}{*}{$\begin{array}{l}\text { Valores recebidos pelos municípios baianos em decorrência do VA e os } \\
\text { critérios ambientais do IDS }\end{array}$} & $r=0,404417$ & $r=0,280013$ \\
\hline & $p=7,701763$ & $p=5,968549$ \\
\hline
\end{tabular}

\section{CONSIDERAÇÕES FINAIS}

Pode-se constatar que a soma dos três critérios adotados na LCE n. 13/1997 guardam forte correlação positiva com o critério do VA, de modo que os municípios com maior produção econômica são duplamente beneficiados no repasse de recursos, fomentando a perpetuação das desigualdades econômicas já existentes.

Os resultados obtidos a partir das propostas legislativas existentes na Bahia mostram que os valores que seriam destinados aos municípios segundo critérios de desempenho ambiental ficariam muito aquém daqueles angariados pelos mesmos municípios em decorrência das atividades econômicas desenvolvidas nos respectivos territórios. Isso pode ter ocorrido porque foi reduzido o número de critérios designados como ambientais, prevalecendo uma visão restritiva sobre o meio ambiente.

A utilização do IDS apresentou como aspecto positivo a baixa correlação com o VA, evitando, assim, que municípios de baixa produção econômica sejam duplamente "punidos" no momento da repartição dos recursos.
Ao avaliar os municípios

multifatorialmente, a repartição dos recursos com base no IDS também incentivaria os gestores municipais a adotarem políticas públicas que melhorem o meio ambiente, analisado este não apenas sob o ponto vista da limitação à utilização de recursos físicos, mas no sentido de harmonizar o bem estar do ser humano com a preservação/conservação dos recursos naturais.

No geral, a utilização do IDS serviu para demonstrar a pertinência de que a repartição de recursos do ICMS, seja feita com base em critérios multifatoriais, constituindo estímulo para a adoção de práticas sustentáveis e evitando privilegiar determinadas atividades à revelia de suas repercussões sociais e, notadamente, ambientais, gerando um círculo virtuoso.

\section{Referências}

BAHIA. Lei Complementar n. 13 de 30 de dezembro de 1997. Assembleia Legislativa do Estado da Bahia. Salvador, BA. Publicação de 30 de dezembro de 1997.

Projeto de Lei Complementar $\mathrm{n}^{\circ} 76$ de 08 de março de 2006a. Altera os dispositivos da Lei Complementar $\mathrm{n}^{\circ}$ 13/1997 de 30 de dezembro de 1997 que regulamenta o inciso II do art. 153 da Constituição do Estado. Deputado Estadual José 
Nunes.

Projeto de Lei no 15.502 de 18 de abril de 2006b. Dispõe sobre a alteração da Lei Complementar $n^{\circ} 13 / 1997$ que regulamenta o inciso II do art. 153 da Constituição do Estado. Deputado José Neto.

. Secretaria da Fazenda do Estado. Disponível em: <http://www.sefaz.ba.gov.br/>. Acesso em: 26 mar. 2018.

BRASIL. Constituição da República Federativa do Brasil. Diário Oficial da União. Brasília, DF. Publicação de 05 de outubro de 1988.

Instituto Brasileiro de Geografia e
Estatística (IBGE). Disponível em: <http://www.ibge.org.br>. Acesso em: 26 mar. 2018.

FERNANDES, L. L. et al. Compensação e incentivo à proteção ambiental: o caso do ICMS ecológico em Minas Gerais. Revista de Economia e Sociologia Rural, Brasília, v.49, n. 3, p. 521544. Jul. 2011.

GRIEG-GRAN, M. Fiscal Incentives for Biodiversity Conservation: The ICMS Ecologico in Brazil. Working Papers, London, n.1, dez. 2000.

MINAS GERAIS. Deliberação Normativa $n^{\circ} 86$ de 17 de junho de 2005. Conselho Estadual de Política Ambiental. Diário do Executivo do Estado de Minas Gerais (COPAM). Belo Horizonte, MG. Publicação de 18 de junho de 2005.

— FUNDAÇÃO JOÃO PINHEIRO,

disponível em: <http://www.fjp.mg.gov.br/>. Acesso em 26 mar. 2018.

NAVIDI, W. Probabilidade e estatística para ciências exatas. Porto Alegre: AMGH Editora, 2012.

ROCCO, R. Dos Instrumentos Tributários para a Sustentabilidade das Cidades. In: COUTINHO, R.; ROCCO, R. (orgs.). O Direito Ambiental das Cidades. Rio de Janeiro: DP\&A, 2004. p. 297349.

RODRIGUES, G. S. de S. C. ICMS ecológico: conceito e repercussões na conservação ambiental do município de Uberlândia, Minas Gerais. Geotextos, Salvador, v. 10, n. 2. 2014.

ROSSATO, M. V. et al. ICMS Ecológico: importância e efetividade como uma política pública de incentivo à melhoria da qualidade ambiental. Interagir: pensando a extensão, Rio de Janeiro, n. 9, p. 59-70, jan./jul. 2006.

SCAFF, F. F.; TUPIASSU L. V. C. Tributação e políticas públicas: o ICMS Ecológico in: Tôrres Heleno Taveira (org). Direito Tributário Ambiental. São Paulo: Malheiros Editores, 2005. p. 724-748.

SEPÚLVEDA S. S. Biograma: metodología para estimar el nivel de desarrollo sostenible de territórios. San José: IICA, 2008.132 p. 